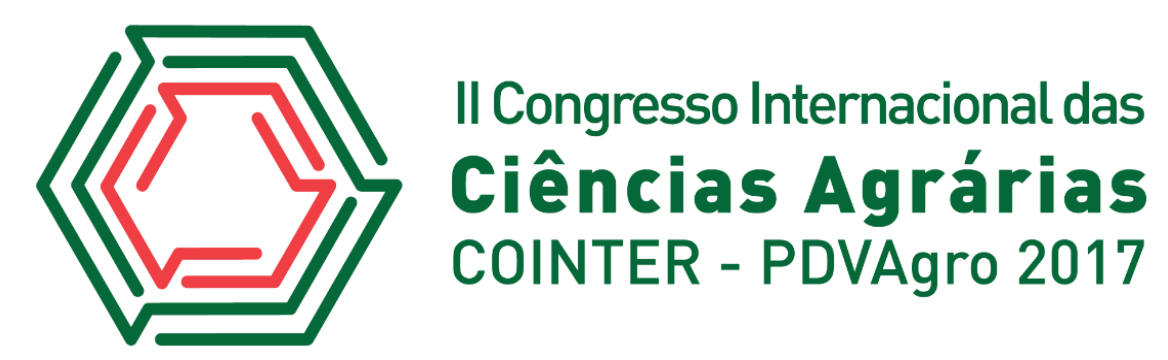

\title{
A PRÁTICA DA DEBICAGEM COMO FERRAMENTA DE ENSINO
}

Apresentação: Relato de Experiência

Manoel Luiz da Silva Neto ${ }^{1}$; Layanne Ferreira Bezerra ${ }^{2}$; João Vitor Celerino da Silva ${ }^{3}$; Maciel Alves Tavares ${ }^{4}$; Guilherme Lyra Amorim ${ }^{5}$

\section{Introdução}

$\mathrm{Na}$ atualidade, a criação comercial de aves poedeiras é feita em sua maioria no sistema de baterias. Esse sistema causa estresse nas aves que devido à pressão social acabam bicando as penas das outras e também cometendo práticas de canibalismo. A perda de penas resultante da agressão de outra ave pode causar tanto problemas econômicos ao produtor como problemas de bem estar às aves. A perda econômica dá-se pelo fato de que a retirada de penas leva a problemas de mantença da temperatura corporal, levando a um aumento no consumo alimentar. Outra perda econômica resultante do canibalismo se refere ao aumento na incidência de ovos bicados (LAGANÁ et al, 2011).

Para evitar que ocorra esse tipo de problema é recomendado que seja realizada a prática da debicagem nos animais. Segundo Laganá et al. (2011), a debicagem é uma prática de manejo recomendada para criações de aves poedeiras (galinhas e codornas) alojadas em elevada densidade de criação. Nesse sentido, foi realizado no processo de formação técnica dos estudantes do curso técnico integrado em agropecuária, do Instituto Federal de Pernambuco Campus Vitória de Santo Antão, aulas práticas de debicagem em aves poedeiras.

\section{Relato de Experiência}

No semestre letivo 2017.1, na disciplina de avicultura, os estudantes do curso técnico integrado em agropecuária do Instituto Federal de Pernambuco Campus Vitória de Santo Antão, realizaram aulas práticas de debicagem. O objetivo das aulas é que os estudantes desenvolvam conhecimentos e saberes sobre a técnica de debicagem visando sua formação para o mercado de

\footnotetext{
${ }^{1}$ Técnico em Agropecuária, Instituto Federal de Pernambuco campus Vitória de Santo Antão, manoel.neto9413@gmail.com

${ }^{2}$ Técnico em Agropecuária, Instituto Federal de Pernambuco campus Vitória de Santo Antão, layanneferreira222@gmail.com

${ }^{3}$ Técnico em Agropecuária, Instituto Federal de Pernambuco campus Vitória de Santo Antão, vitorsjs2008@hotmail.com

${ }^{4}$ Bacharelado em Agronomia, Instituto Federal de Pernambuco campus Vitória de Santo Antão, macieltavares15@gmail.com

${ }^{5}$ Professor Doutor, Instituto Federal de Pernambuco campus Vitória de Santo Antão, guilherme.amorim@vitoria.ifpe.edu.br
} 
trabalho.

Segundo Laganá et al. (2011), a debicagem é uma prática de manejo recomendada para criações de aves poedeiras (galinhas e codornas) alojadas em elevada densidade de criação. É o principal método utilizado para coibir a bicagem de penas e o canibalismo na indústria avícola.

A debicagem consiste num processo cirúrgico de corte e cauterização do bico das aves. Ela é uma das práticas mais importantes na avicultura, tendo em vista que, sua realização visa acabar com a bicagem das penas e o canibalismo dentro do aviário. Ao realizar essa prática deve-se tomar bastante cuidado, visto que erros podem afetar o desenvolvimento da ave e consequentemente sua produtividade. Para realização da prática são feitas algumas recomendações para atingirmos o objetivo, tais como: os melhores horários são o início da manhã ou final da tarde, evitando horários mais quentes, o que causaria estresse nas aves; a lâmina do debicador deve estar a uma temperatura de aproximadamente $700^{\circ} \mathrm{C}$; o corte do bico

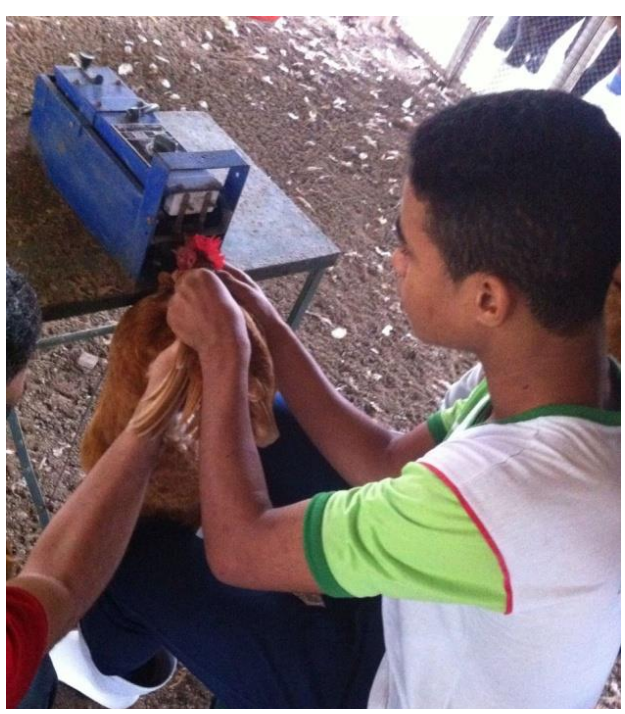

Figura 1. Debicagem de Aves. Fonte: Própria. deve ser realizado lentamente para que a lâmina realize também a cauterização; para evitar hemorragia deve-se fornecer aos animais vitamina K, 3 dias antes e 3 dias depois da debicagem.

Seguindo as recomendações, os estudantes realizaram a debicagem em 30 aves poedeiras do setor de avicultura do Instituto Federal de Pernambuco Campus Vitória de Santo Antão, visando aplicar o conhecimento técnico adquirido em sala para o desenvolvimento de conhecimento prático na sua formação.

\section{Considerações}

Com a realização da prática de debicagem em aves, seguindo as recomendações técnicas, os estudantes puderam vivenciar e desenvolver competências e saberes que contribuem fortemente para sua formação profissional, visando o atendimento as exigências do mercado de trabalho.

\section{Referências}

LAGANÁ, C. INFLUÊNCIA DO MÉTODO DE DEBICAGEM E DO TIPO DE BEBEDOURO NO DESEMPENHO DE CODORNAS JAPONESAS. Disponível em: $<$ http://www.aptaregional.sp.gov.br/acesse-os-artigos-pesquisa-e-tecnologia/edicao-2011/2011julho-dezembro/856-influencia-do-metodo-de-debicagem-e-do-tipo-de-bebedouro-nodesempenho-de-codornas-japonesas/file.html> Acesso em: 24 Set. 2017. 